\title{
卧位運功と坐位運䃼における呼吸循環反応の違いについて
}

\author{
高橋哲也* 田辺一彦** 中山 大** 長田尚彦** \\ 山田純生 ${ }^{* *}$ 石黒友康* 伊東春樹** 村山正博**
}

\section{CARDIOPULMONARY RESPONSE DURING SUPINE AND SITTING BICYCLE EXERCISE}

\author{
Tetsuya Takahashi, Kazuhiko Tanabe, Masaru Nakayama, Naohiko Osada, \\ Sumio Yamada, TOMOyasu Ishiguro, Haruki ItoH and Masahiro Murayama
}

\begin{abstract}
The difference in cardiopulmonary response between supine exercise and sitting exercise was assessed by the following protocols.

1) Cardiopulmonary exercise testing utilizing the ramp protocol with a bicycle ergometer (20 $\mathrm{W} / \mathrm{min}$ ) was performed by nine healthy Japanese men (mean age, 19.9 $\mathrm{yr}$ ) in a sitting and a supine position. Oxygen uptake, heart rate and blood pressure were measured during the test. Blood was sampled in order to measure noradrenaline (NA) and angiotensin II (ANG II) in the resting control state and immediately after exercise.

2) Single-level exercise testing at $100 \mathrm{~W}$ was performed on another day. The cardiac index (CI) was computed from the cardiac output, which was measured using the dye-dilution method in the resting control state and during exercise.

The results were as follows:

1) Heart rate and blood pressure during exercise had a tendency to be lower in the supine position compared to the sitting position, although not significantly.

2) Anaerobic threshold (AT) was lower in the supine position than in the sitting position exer cise, $(18.3 \pm 2.6 \mathrm{ml} / \mathrm{kg} / \mathrm{min}$ and $21.7 \pm 1.9 \mathrm{ml} / \mathrm{kg} / \mathrm{min}$, respectively).

3) NA and ANG II in the supine position were slightly lower than in the sitting position.

4) At rest, the $\mathrm{CI}$ in the sitting position was significantly less than in the supine position; however, the $\mathrm{CI}$ during the $100 \mathrm{~W}$ exercises was the same in both the supine and sitting positions.

It is concluded that blood flow to active muscle during $100 \mathrm{~W}$ exercise is lower in the supine than in the sitting position. This is thought to be due to changes in blood redistribution and lowered blood flow to active muscle in the supine position, creating a lower AT.
\end{abstract}

(Jpn. J. Phys. Fitness Med. 1995, $44:$ 105 112)

key words : Cardiopulmonary response, Body position, Blood redistribution, Anaerobic threshold.

\section{I. 粕}

心肺運動負荷試験から得られる Anaerobic Threshold (AT) · peak $\dot{\mathrm{VO}}_{2}$ は、健常人の運動酎容
能評価や，心疾患患者の重症度評価などの指標と して有用と考えられている20.23).これらはトレッ ドミル，エルゴメータなどの運動種目，あるいは トレーニング内容などによっても影響を受けるこ
*聖マリアンナ医科大学東横病院

リハビリテーション部

テ211 神奈川県川崎市中原区小杉町3-435

**桯マリアンナ医科大学病院

ハートセンター

干216 神奈川県川崎市宮前区营生2-16-1

***聖マリアンナ医科大学病院

リハビリテーション部

干216 神奈川県川崎市宮前区菅生2-16-1
Dept. of Rehabilitation Medicine, St. Marianna University School of Medicine Toyoko Hospital 3-435 Kosugi-cho

Nakahara-ku Kawasaki-shi Kanagawa, 211 Japan

Heart Center, St. Marianna University School of Medicine

Hospital 2-16-1 Sugao Miyamae-ku Kawasaki-shi

Kanagawa, 216 Japan

Dept. of Rehabilitation Medicine, St. Marianna University School of Medicine Hospital 2-16-1 Sugao Miyamae-ku Kawasaki-shi

Kanagawa, 216 Japan 
とが知られている1.13).

心筋梗塞後の心臓りハビリテーションなどの臨 床ではトレッドミル運動や坐位自転車エルゴメー 夕運動などの，立位あるいは坐位運動が広く用い られている．その一方で運動負荷シンチグラムや 心臓カテーテル中の運動負荷には，検査手技上の 制約から臥位自転車エルゴメータなどの臥位運動 が用いられることも少なくない。このような臥位 運動負荷試験結果を正確に評価するためには，坐 位運動と臥位運動の生理学的な差を理解しておく ことは極めて重要といえる.

さらには近年, 高齢者及び障害者の体力維持增 強の観点 ${ }^{21)}$ から, 安全かつ実用的な有酸素運動 の試みが模索され，背もたれ付き自転車エルゴ メータの開発や臥位での有酸素運動が注目されて いる，従って，運動肢位の違いが各種生体反応に 及ほす影響を理解することは必須のものとなって きた。

そこで今回我々は，運動肢位の違いが呼吸循環 器系にどのような影隦をもたらすかについての基 礎的研究として，健常人を対象に臥位と坐位にて 運動負荷試験を行い，呼吸循環動態，心拍出量動 態，各種ホルモン動態について検討した。

\section{II. 対象と方法}

対象は健常男性 9 例. 平均年齢 $19.9 \pm 1.5$ 歳, 平均身長 $172.6 \pm 4.5 \mathrm{~cm}$, 平均体重 $65.6 \pm 8.9 \mathrm{~kg}$ で，全対象者が運動部に所属していた。

運動負荷試験にはTS Health System 社製 Space Cycle SSR を用いて, 3 分間の安静, 20 watts, $60 \mathrm{rpm}$ で 3 分間の Warming up の後，毎 分 20 Watts 漸增する ramp 負荷を 180 Watts ま で行った。これを同一被検者にて坐位と臥位にて ランタムに行い，測定の間隔は基本的に1週間と した.

呼気ガスの測定は，ミナト医科学社製 Respiromoniter RM-300 を用い, breath by breath 法に て連続的に行った，運動負荷心電図，心拍数測定 はフクダ電子製負荷心電図処理装置 ML-5000, 血圧測定はコーリン製自動血圧計 STBP-780 を 用い，それぞれ 1 分毎に測定した。さらに，嫌気
性代謝闘值 Anaerobic Threshold (AT)は，分時換 気量 $\left(\dot{\mathrm{V}}_{\mathrm{E}}\right)$ /炭酸ガス排出量 $\left(\dot{\mathrm{V}} \mathrm{CO}_{2}\right)$ の増加なしに,

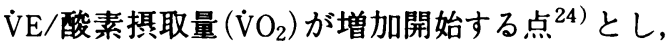
3 名の reviewer によりグラフから決定した。さ らに肘静脈にカテーテルを留置した後，それぞれ の検查肢位で30分間安静にし，安静時と運動負荷 終了時に採血し，ノルアドレナリン，アンギオテ ンシン II を測定した.ノルアドレナリンの測定は, 酸化アルミナ吸着抽出後, 高速液体クロマトグラ フィー(HPLC)にて行い，アンギオテンシン II は RIA 法にて行った。また別の日に両肢位で 6 分 間の 100 watts 単一負荷を施行し, 安静時と 100 watts 負荷時に日本光電社製希䣋式心拍出量計算 装置 MLC-4200 を用い, 固定した时静脈カテー テルより $5 \mathrm{mg}$ のジアグノグリーン®注(第一製 薬)を注入し，色素希釈法による心拍出量を測定 し，さらにその結果から心係数を算出した。

なお，実験対象者全員に本研究の主旨を説明し， 同意を得た後に行った，統計学的手法は，主とし て $\mathrm{t}$-検定を用いて行い，有意水準は原則として 両側 $5 \%$ 末満を有意と判定した。

\section{II. 菬果}

A. 心拍数 (HR), 血圧 (SBP, DBP) 動態

坐位および臥位運動時の HR, SBP, DBP の変化 を図 1 に示す. HR, SBP, DBP は有意な差はない ものの全般的に坐位運動で高値を示す傾向があっ た。

B. 酸素摄取量 $\left(\dot{\mathrm{V}} \mathrm{O}_{2}\right), \Delta \dot{\mathrm{V}} \mathrm{O}_{2} / \Delta$ Work Rate, 酸素脈 $\left(\mathrm{O}_{2}\right.$ Pulse $)$ 動態

坐位および卧位運動時の $\mathrm{VO}_{2}$ の変化を図 2 に 示す. 安静時の $\mathrm{V}_{2}$ は坐位で $5.1 \pm 0.7$ $\mathrm{ml} / \mathrm{kg} / \mathrm{min}$, 臥位で $4.3 \pm 0.5 \mathrm{ml} / \mathrm{kg} / \mathrm{min}$. Warm ing up 時の $\mathrm{VO}_{2}$ は坐位で $10.8 \pm 0.7 \mathrm{ml} / \mathrm{kg} / \mathrm{min}$, 臥位で $9.8 \pm 0.9 \mathrm{ml} / \mathrm{kg} / \mathrm{min}$ と坐位条件で有意に 大きい值を示した $(\mathrm{p}<0.05)$ ．また AT 時の $\mathrm{V}_{2}$ も坐位で $21.7 \pm 1.9 \mathrm{ml} / \mathrm{kg} / \mathrm{min}$, 臥位で $18.3 \pm$ $2.6 \mathrm{ml} / \mathrm{kg} / \mathrm{min}$ と坐位条件で有意に大きい值を示 した $(\mathrm{p}<0.01)$ ．負荷終了時の $\mathrm{V}_{2}$ は，坐位で $35.8 \pm 3.1 \mathrm{ml} / \mathrm{kg} / \mathrm{min}$, 臥 位で $33.7 \pm 4.1$ $\mathrm{ml} / \mathrm{kg} / \mathrm{min}$ と坐位運動で高値を示す傾向があった 


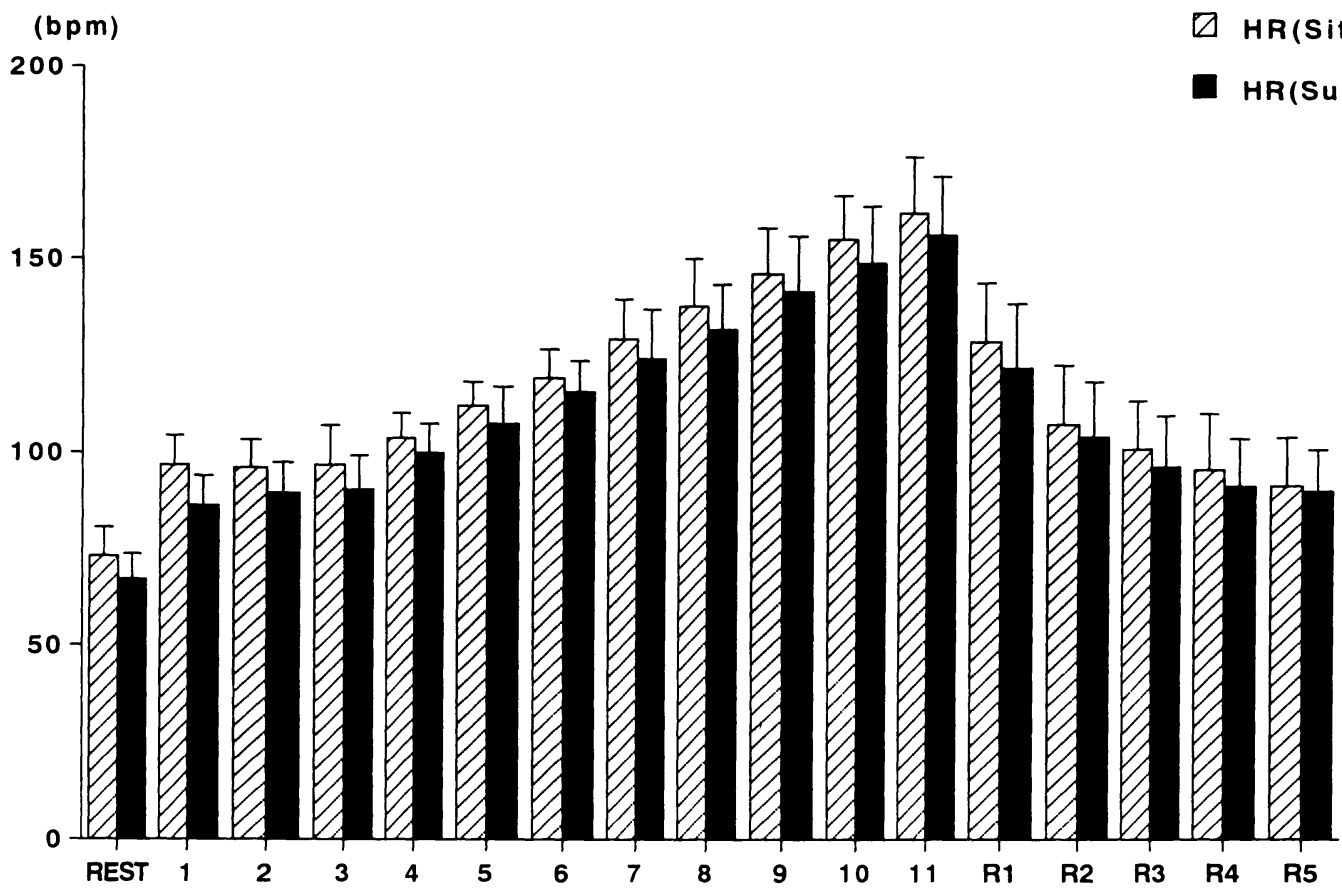

Fig. 1-1. Variations in heart rate (HR) in response to graded sitting and supine exercise and recovery phase. Values are means $\pm \mathrm{SD}$.

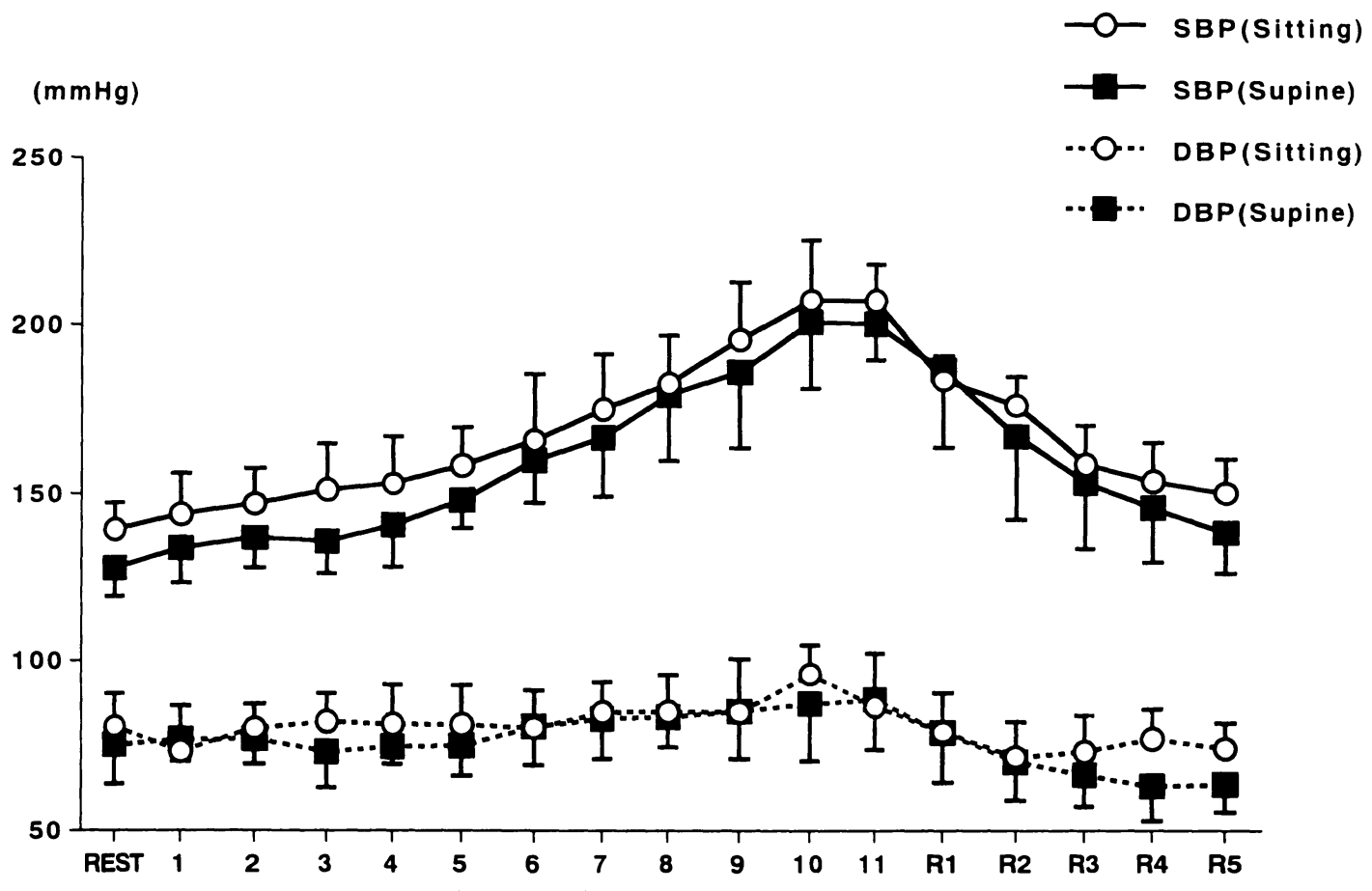

Fig. 1-2. Blood pressure (SBP, DBP) in response to graded sitting and supine exercise and recovery phase. Values are means $\pm S D$. 


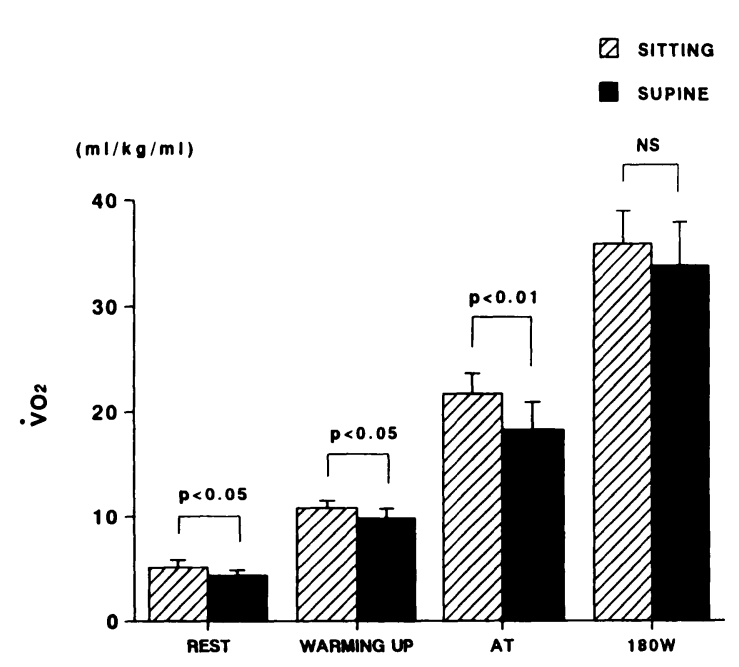

Fig. 2. Variations in oxygen uptake in response to greded sitting and supine exercise. Values are means $\pm \mathrm{SD}$

が有意な差はみられなかった。

AT 時の HR は, 坐位で $123.1 \pm 7.8 \mathrm{bpm}$, 臥 位で $114.7 \pm 9.4 \mathrm{bpm}$ と有意な差はないものの， 坐位運動で高値であった.ささら運動開始後 AT に達するまでの時間は, 坐位で $203.0 \pm 33.8 \mathrm{sec}$, 臥位で $163.7 \pm 31.5 \mathrm{sec}$ と坐位条件で有意に長 かった $(\mathrm{p}<0.05)$.

個体の酸素輸送能を示す指標である酸素攝取量 の変化率/運動負荷増加率 $\left(\Delta \dot{\mathrm{VO}}_{2} / \Delta\right.$ Work Rate $)$ は, 坐位条件で $11.0 \pm 1.1 \mathrm{ml} / \mathrm{W}$, 臥位条件で $10.3 \pm 1.2 \mathrm{ml} / \mathrm{W}$ と有意な差はみられなかった (表 1 ).

酸素脈 $\left(\mathrm{O}_{2}\right.$ Pulse) は各時期で有意な差はみられ なかったが坐位条件で高値を示した(図 3 ).

C.ノルアドレナリンおよびアンギオテンシン

\section{II 動態}

次に安静時及び負荷終了時のノルアドレナリ ン, アンギオテンシン II 值を図4に示す.ノル アドレナリンは安静時は坐位 $365.9 \pm 130.6$ $\mathrm{pg} / \mathrm{ml}$, 臥位 $274.6 \pm 94.2 \mathrm{pg} / \mathrm{ml}$ と坐位で高値を 示し, 負荷終了時は坐位 $1385.5 \pm 484.7 \mathrm{pg} / \mathrm{ml}$, 臥位 $1032.3 \pm 543.6 \mathrm{pg} / \mathrm{ml}$ と坐位条件で高值傾向 を示した．またアンギオテンシン II は安静時坐位 $14.8 \pm 6.4 \mathrm{pg} / \mathrm{ml}$, 臥位 $8.0 \pm 4.9 \mathrm{pg} / \mathrm{ml}$, 負荷終 了時坐位 $16.8 \pm 4.6 \mathrm{pg} / \mathrm{ml}$, 臥位 $11.4 \pm 6.1$ $\mathrm{pg} / \mathrm{ml}$ と有意な差はないものの坐位で高値を示し た.

\section{D. 心係数動態}

心拍出量から計算した心係数は安静時には坐位 条件で $2.5 \pm 0.71 / \mathrm{m}^{2} / \mathrm{min}$, 卧位条件で $3.3 \pm 0.6$ $1 / \mathrm{m}^{2} / \mathrm{min}$ と臥位で有意に高値を示したものの, 100 watts 運動負荷時には, 坐位条件で $7.6 \pm 1.5$ $1 / \mathrm{m}^{2} / \mathrm{min}$, 卧位条件で $7.91 \pm 1.71 / \mathrm{m}^{2} / \mathrm{min}$ と

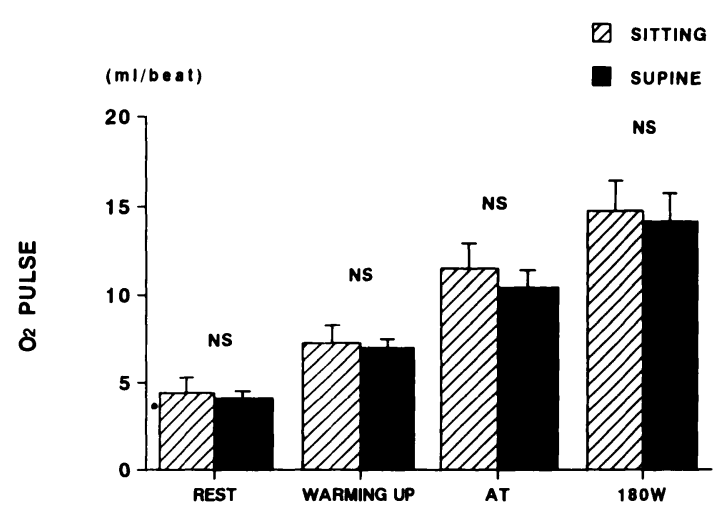

Fig. 3. Variations in oxygen pulse in response to greded sitting and supine exercise. Values are means $\pm \mathrm{SD}$.

Table 1. Comparison of oxygen uptake $\left(\mathrm{V}_{2}\right)$ and heart rate (HR) at anaerobic threshold (AT), exercise time 0 to AT among sittng exercise and supine exercise. And $\Delta \dot{V}_{2} / \Delta$ Work Rate during each incremental exercise

\begin{tabular}{ccccc}
\hline & $\dot{\mathrm{VO}}_{2}-\mathrm{AT}(\mathrm{ml} / \mathrm{kg} / \mathrm{min})$ & $\mathrm{HR}-\mathrm{AT}(\mathrm{bpm})$ & Exercise Time $(\mathrm{sec})$ & $\Delta \dot{\mathrm{VO}}_{2} / \Delta \mathrm{Work}_{\mathrm{Rate}}$ \\
\hline Sitting exercise & $21.7 \pm 1.9$ & $123.1 \pm 7.8$ & $203.0 \pm 33.8$ & $11.1 \pm 1.1$ \\
& $\mathrm{p}<0.01$ & $\mathrm{P}<0.06$ & $\mathrm{P}<0.05$ & $\mathrm{NS}$ \\
Supine exercise & $18.3 \pm 2.6$ & $114.7 \pm 9.4$ & $163.7 \pm 31.5$ & $10.3 \pm 1.2$ \\
\hline
\end{tabular}

$\dot{\mathrm{V}} \mathrm{O}_{2}-\mathrm{AT}: \dot{\mathrm{VO}_{2}}$ at anaerobic threshold.

HR-AT : heart rate at anaerobic threshold. 


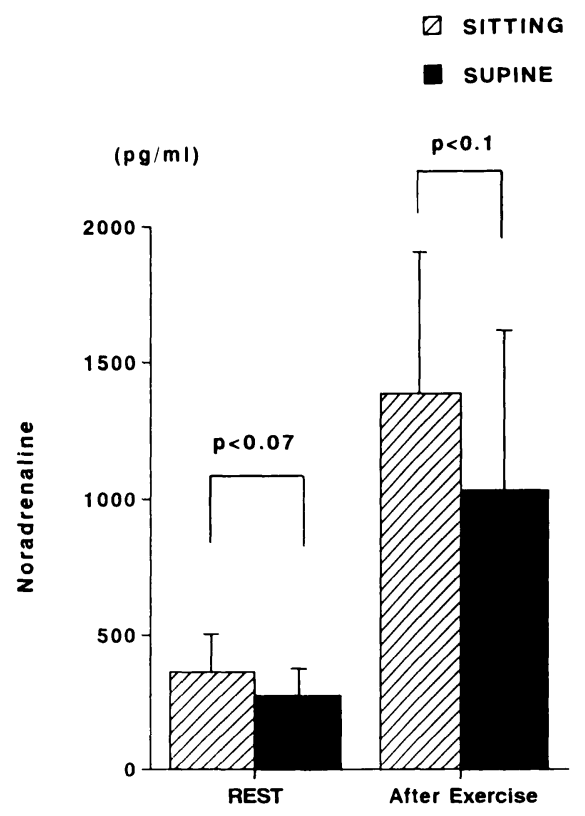

Fig. 4-1. Plasma noradrenaline in the resting control state and after exercise. Values are means $\pm S D$.

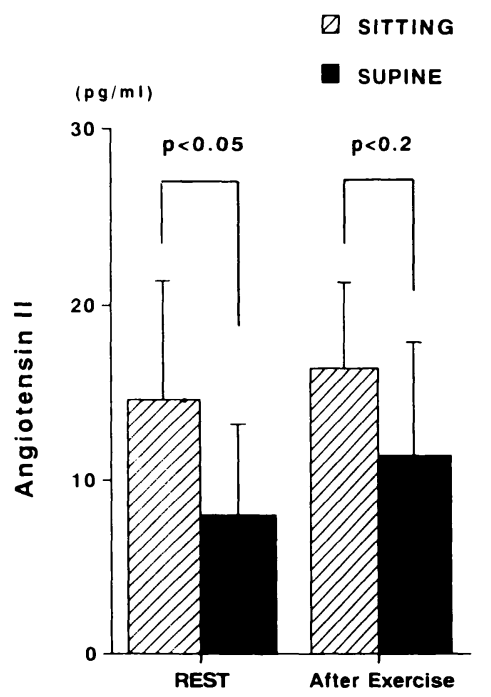

Fig. 4-2. Angiotensin II in the resting control state and after exercise. Values are means \pm SD.

ほほ同等の値を示した(図 5 ).

$$
\text { N. 考察 }
$$

臥位運動と坐位運動の呼吸循環動態に関して,

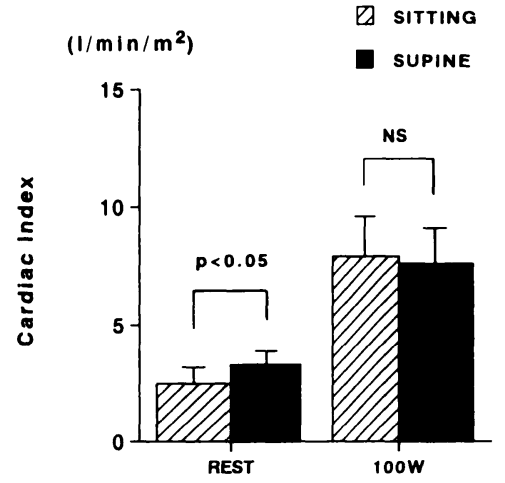

Fig. 5. Cardiac index in the resting control state and during 100 watts exercise. Values are means $\pm S D$.

Ástrand $ら^{1)}$ は 7 人の健常人を対象に運動負荷試 験を実施し, 臥位運動時の最大酸素攝取量は坐位 運動に比べて14\%有意に低值を示すと述べ，この 違いについて，臥位ではなめらかなクランク運動 ができないと運動の機械効率的観点から考察して

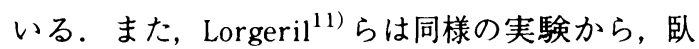
位運動は坐位運動に比べて最大心拍数が低値であ ることや, 運動時間および最大運動負荷量が低值 であることの原因として，運動に動員される筋量 が少ないことや運動の習熟度が関係しているとし ている．しかし今回の我々の実験では従来のもの と異なり, 背もたれがある椅子坐位式自転車エル ゴメータを用いているため, 坐位保持のための抗 重力筋の活動は最小限に抑えられていると考えら れ, 臥位運動と坐位運動の酸素攝取量の差は, 重 力の違いなどによる心拍出量動態に基づくことが 推察される.

安静臥位時の 1 回拍出量は, 静脈環流が多いこ となどから安静坐位時に比べて高值を示すことが 推察される. Stenberg ら ${ }^{18)}$ はアスリートを対象 として色素希釈法で心拍出量を測定し, 安静臥位 時の 1 回拍出量は最大 1 回拍出量の $75 \sim 81 \%$, 安 静坐位時は46〜50\%であるとした。また運動中は 臥位で $\mathrm{V}_{2} \max$ の $50 \%$, 坐位で $\dot{\mathrm{VO}}_{2} \max$ の70 $80 \%$ の負荷強度で 1 回拍出量はその最大値を示 し, それぞれの肢位における 1 回拍出量の最大値 はほほ同等の值であったとしている。また， 
Bevegård ら ${ }^{3)}$ は $800 \mathrm{kpm} / \mathrm{min}$ の運動で, 1 回拍 出量の増加は臥位で $9 \%$, 坐位で $48 \%$ であり, そ の後は運動強度が増加しても 1 回拍出量に変化は ないと報告し, 1 回拍出量の変化は運動開始後比 較的早期に起こることを報告している.

同様に Poliner ら ${ }^{14)}$ は, $300 \mathrm{kpm} / \mathrm{min}(50 \mathrm{w})$ の 低負荷で, 坐位運動と臥位運動の 1 回拍出量の違 いはすでになかったと報告し, Boucher ら5)も AT レベルもしくはそれ以前に 1 回拍出量は最高 値を示すとしている.これらの報告は, 最大運動 負荷レベルより軽い負荷レベルで 1 回拍出量が最 大值に到達することで一致しており，本研究にお いても, 運動中の心拍数は肢位によってさほど差 がみられなかったことから, 最大 1 回拍出量到達 後は心拍出量に著明な差はないと考えられる.

心拍出量に関して, Stenberg ら ${ }^{18)}$ は低い運動 負荷時には, 坐位運動より臥位運動で高い心拍出 量を示し, 運動強度が高くなると坐位運動でやや 高値を示すと報告している. 今回我々は安静時と $100 \mathrm{~W}$ 負荷時に心拍出量を測定し, その結果か ら心係数を算出したところ, 心係数は安静時では 臥位で高く, $100 \mathrm{~W}$ 運動負荷時にはほほ同等の 值を得た。したがって，これをFick の公式, 酸 素摄取量=心拍出量 $\times$ 動静脈酸素較差 ${ }^{13)}$ に当て はめると, 本検討における運動時酸素掑取量は動 静脈酸素較差に規定されると考えられる2)4).

運動中の最大動静脈酸素較差は, 拍出された血 液量の大部分を活動筋に流入させることのできる 個人の能力にかなり影響されると考えられてい $ろ^{13)}$. 運動に際して活動筋の血流増大は, 心拍 出量の増大と, 活動筋における選択的血管拡張, 非活動筋の選択的血管収縮による血流再配分に よって規定される. 前者の心拍出量に関しては安 静時では臥位で高値を示すものの, $100 \mathrm{~W}$ atts 単 一負荷時までにはほほ同等になることから, 今回 得られた結果は, 末梢の血流量や血流再配分較差 の増大が関与するものと考えられる. 運動中の活 動筋血流量に関して, Folkow ら ${ }^{8)}$ は毎秒 1 回の 律動運動中の腓腹筋血流量を臥位と $60^{\circ}$ 直立位で 比較し, $60^{\circ}$ 直立位の方が腓腹筋血流量は増加す ると報告している. Folkow らの結果から, 坐位
運動の方が臥位運動時に比べて活動筋への血流量 が多いことが推察できる.また, 運動筋の血管トー ヌスを制御する因子として松井ら ${ }^{12)}$ は自律神経 系, 末梢組織における代謝性機序 (組織 $\mathrm{pH}, \mathrm{PCO}_{2}$, $\mathrm{PO}_{2}$, 浸透圧, $\mathrm{K}^{+}$, アデノシンなど), 血管内皮 由来の拡張物質や収縮物質などを挙げているが, 本研究では非活動筋の選択的血管収縮による血流 再配分に着目し，血管収縮作用を持つノルアドレ ナリンとアンギオテンシン II 2 つのホルモン動 態に関して検討した. アンギオテンシン IIは腹腔 内などの非活動笳への血管の収縮を引き起こし, この作用はアンギオテンシン II の血管に対する直 接的作用と, 交感神経系の活動をより高める間接 的作用の両者が推察されている ${ }^{15)}$ 。また坐位に おけるアンギオテンシン II 分泌はアルドステロ ン分泌を刺激し, $\mathrm{Na}$ 貯留の方向に作動し, 坐位 姿勢へ適応させる作用を有するとされる ${ }^{16)}$. 一 方, 運動中のカテコラミン, アンギオテンシン II は強度依存的に分泌量が増大するといわれ, 特に ノルアドレナリンは最大運動に近づくに従い，ま たは ATを境に指数関数的に増加するといわれ ている 6.9 .10 .17 .19$)$. 本研究では, 安静時にはアン ギオテンシン II は, 坐位で有意に大きい値を示し, 運動時には有意な差はないものの, ノルアドレナ リン, アンギオテンシン II ともに, 全般的に坐位 で高値を示していた.このことは坐位運動時には, 臥位運動時に比べて非活動筋の末梢血管緊張が高 まり，より多くの血流が活動筋へ配分されること を示唆している.

特に今回の実験で特徴的なことは, 臥位運動で は坐位運動に比べ, AT に到達するまでの運動時 間が短く, AT 時の $\mathrm{VO}_{2}$ は低值を示すことであ る.ATと活動筋量の間には密接な関係があると いう事から ${ }^{22,25)}$, 臥位運動で AT が低いことは 実際に動員される活動筋量が少ないことが予想さ れる.

しかし，その一方で Bevegárd ら ${ }^{3)}$ は臥位運動 は坐位運動に比べて血中乳酸濃度が高いことを指 摘し,また, Eiken ${ }^{7)}$ は, Lower Body Negative Pressure (LBNP)により下肢血流量を増加させた 状態で臥位運動を行う時に比べ，LBNP を負荷し 
ない状態での臥位運動では，血中乳酸濃度の上昇 が早いことから，血流量の大小により，嫌気的代 謝への移行速度が異なる事を報告している．今回 の実験では血中乳酸濃度の測定は行っていないた め, 乳酸産生とこれらのホルモン動態との関連は 言及できないが, 臥位運動と坐位運動では活動筋 の血流量に差があり，臥位運動においては運動負 荷に対する活動筋に応じた血流量が充分に供給さ れず，運動筋のAnaerobicな代謝を喚起しやすい 事が示唆される.

\section{V. 結語}

健常男性 9 人を対象に, 臥位と坐位にて運動負 荷試験を行い，呼吸循環動態の違いを検討した。

A .血圧, 心拍数, 酸素摂取量は坐位運動で高 値を示した。

B. 臥位運動で AT 時の酸素攝取量, 心拍数 が低く，早期にATに到達した。

C．坐位運動では重力の影響に加えて，血管収 縮作用のあるホルモンの分泌が多く，活動筋によ り多くの血液を供給していることが推察された。

D．臥位運動は活動筋血流量が少ないことか ら，早期にアシドーシスになり，AT が低いこと が示唆された。

\section{文}

\section{堿}

1) Ȧstrand PO, B Saltin (1961): Maximal oxygen up. take and heart rate in various types of muscular activity. J. Appl Physiol., 16, 977-981.

2) Ȧstrand PO, K Rodahl; 朝比奈一男監訳, 浅野勝己 訳(1979): オストランド運動生理学.VI循環, 大修 館書店. 東京, 83-136.

3) Bevegárd S, A Holmgren, B Jonsson (1963) : Circulatory studies in well trained athletes at rest and dur. ing heavy exercise, with special reference to stroke volume and the influence of body position. Acta Physiol Scand., 57, 26-50.

4) Bevegárd BS, JT Shepherd (1967) : Regulation of the circulation during exercise in man. Physiol Rev., 47, 178-213.

5) Boucher CA, MD Anderson, MS Schneider, JH Hurphy, RD Okada, DJ Kanarek (1985) : Left ventricular function before and after reaching the anaerobic threshold. Chest, 87(2), 145-140.

6) Deuster PA, CA Luger, JE DeBolt, LL Bernier, UH Trostmann, SB Kyle, LC Montgomery, DL Loriaux (1989): Hormonal and metabolic responces of untrained, moderately trained, and high trained men to three exercise intensities. Metabolism, 38(2), 141-148.

7) Eiken O (1988) : Effects of increased muscle perfusion pressure on responses to dynamic leg exercise in man. Eur J Appl Physiol., 57, 772-776.

8) Folkow B, U Haglund, M Jodal, O Lundgren (1971): Blood flow in the calf muscle of man during heavy rhythmic exercise. Acta Physiol Scand., 81, 157-163.

9）藤井宣晴，鍋倉賢治，権五晟，山崎文夫，本間 幸子, 池上晴夫 (1992)：運動強度の増大に対する心 拍数および血獎カテコールアミンの応答, 体力科 学, 41, 313-321.

10）井川幸雄, 鈴木政登, 塩田正俊 (1984)：カテコール アミン、レニン、アンギオテンシンおよび cAMP 反応に及ほす運動強度の影響, 体育科学, 12 , 201-212.

11) Lorgeril M, J Laurier, V Stucki, B Meier, A Righetti, MG Bourassa (1990): Computerized determination of lactate threshold during three modes of exercise. Heart-Vassels., 5(2), 76-80.

12）松井 忍，田村暢熙 (1993)：運動に伴う血中アデノ シン動態一健常若年男性における検討一，体力科 学, 42, 265-270.

13) McArdle WD, FI Katch \& VL Katch ; 田口員善, 矢 部京之助, 宮村実晴, 福永哲夫監訳 (1992) : 運動生 理学, 第17章 心血管系の機能, 杏林書院, 東京, 269-288.

14) Poliner LR, GJ Dehmer, SE Lewis, RW Parkey, CG Blomqvist, JT Willerson (1980) : Left ventricular performance in normal subjects: A comparison of the responses to exercise in the upright and supine positions. Circulation, 62, 528-534.

15) Rowell LB (1986): Human Circulation-Regulation during physical stress-. Oxford University Press. New York, 78-95.

16) Rowell LB (1986): Human Circulation-Regulation during physical stress-. Oxford University Press. New York, 137-173. 
17) Staessen J, R Fagard, $P$ Hespel, $P$ Lijnen, L Vanhees, A Amery (1987): Plasma renin system during exercise in normal men. J Appl Physiol., 63 (1) , 188-194.

18) Stenberg J, PO Ảstrand, B Ekblom, J Royce, B Saltin (1967): Hemodynamic response to work with dif. ferent muscle groups, sitting and supine. J. Appl. Physiol., 22, 61-70.

19）田辺一彦, 長田尚彦, 野田聖一, 山本雅庸, 大宮 一人, 伊東春樹, 亀谷 学, 村山正博, 須階二朗 (1994) : 120\% AT レベル単一負荷における循環動 態とカテコラミン動態, J. Cardiology, 24 (1), 6169.

20）谷口興一編集 (1993) : 心肺運動負荷テスト一呼気ガ ス分析による心肺疾患の新しい見方一，南江堂， 東京.
21）山田純生 (1994)：理学療法と体力低下予防、その低 下機序と対処方法の考え方, PT ジャーナル, 28(6), 378-382.

22) Wasserman $K(1984):$ The anaerobic threshold measurement in exercise testing. Clin Chest Med., 5 , 77-88.

23) Wasserman K, JE Hansen, DY Sue, BJ Whipp; 谷口 興一, 吉田敬義共訳 (1989) : 運動負荷テストとその 評価法, 南江堂, 東京, 36-77.

24) Wasserman K, BJ Whipp (1975) : Exercise physiology in health and disease. Ann Rev Respir Dis., 112, 219-249.

25) Withers RT, WM Sherman, JM Miller, DL Costill (1981): Specificity of the anaerobic threshold in endurance-trained cyclists and runners. Eur J Appl Physiol., 47, 93-104. 